Note

\title{
Expression of Truncated Pro-Opiomelanocortin Gene Transcript in Human Leukemia Cell Lines
}

\author{
Koji MURAO, MaKoto SATO, Hitomi IMACHI, Hidemi OHE, MASAmi NAGAI, \\ MICHIO NIIMI*, TOSHIHIKO ISHIDA, AND JIRO TAKAHARA
}

First Department of Internal Medicine and *Central Laboratory, Kagawa Medical School, Kagawa 761-0793, Japan

\begin{abstract}
Although previous studies have suggested that human peripheral blood mononuclear cells (PBMCs) may express pro-opiomelanocortin (POMC) mRNA and synthesize its related peptides, the patho-physiological role of POMC expressed in peripheral cells is not known. In this study, we investigated the POMC gene expression in various types of human leukemia cell lines by Northern blot analysis and the reverse transcribed-polymease chain reaction (RT-PCR) method. The POMC mRNA was not detected by Northern blot analysis in all cell lines tested except the Jurkat cell line which is derived from T-lymphoblastic leukemia. The POMC mRNA expressed in the Jurkat cells was smaller than that in the human anterior pituitary gland. The RT-PCR method revealed that a truncated-POMC transcript could be detected not only in lymphoblastic leukemia cells but also in erythroid and myeloid cells. Interestingly, two cell lines of monocytic leukemia, J-111 and U937, did not express the truncatedPOMC mRNA. Treatment with concanavalin-A stimulated truncated POMC mRNA expression and ACTH-like immunoreactivity in lymphoblastic leukemia cells with T-(Jurkat) and B-(BALL-1) lymphocyte phenotypes. These results confirm that human leukemia cells except for monocytic cells express a truncated-POMC mRNA as well as in the human normal PBMC.
\end{abstract}

Key words: POMC, ACTH, Leukemia cells, RT-PCR, Lymphocyte

(Endocrine Journal 45: 399-405, 1998)

IT HAS recently been shown that human peripheral blood mononuclear cells (PBMCs) may synthesize and release various hypothalamic and pituitary hormones such as $\mathrm{CRH}$, GH-releasing hormone (GRH), ACTH, GH, and PRL [1]. Furthermore, a variety of receptors including those of the neuropeptides have been shown to be present on PBMC [2], so that the immune, neural and endocrine systems may interact through a network of shared ligands and receptors.

ACTH derives from the post-translational processing of pro-opiomelanocortin (POMC), a

Received: June 30, 1997

Accepted: January 30, 1998

Correspondence to: Dr. Makoto SATO, First Department of Internal Medicine, Kagawa Medical School, Kita-gun, Miki-cho, 1750-1, Kagawa 761-0793, Japan complex polypeptide precursor molecule [3]. In addition to its classic neuroendocrine effects, ACTH has a variety of immunoregulatory actions ranging from suppression of interferon production [4] and regulation of antibody responses [5] to enhancement of B cell growth and differentiation [6] and memory cytotoxic activity [7]. Recent studies have shown the presence of both POMC peptides and mRNA within the human PBMC [1, $8-11]$, but there is no evidence that POMC mRNA can be produced in human hematopoietic cells with different phenotypic characteristics. The present study was undertaken to investigate the presence of POMC mRNA in human leukemia cells with different lineages. We have also examined the effects of concanavalin A (Con-A) on POMC mRNA and ACTH release in these cells. 


\section{Materials and Methods}

Isolation of human PBMCs and culture of various types of human leukemia cell lines

Human PBMCs were obtained from the venous blood of normal volunteers. The PBMCs were isolated at room temperature by Ficoll-Paque (Pharmacia LKB, Biotechnology Inc, Piscataway, NJ) gradient according to the manufacture's instruction. Briefly, heparinized blood was diluted in a 2:1 ratio with $0.1 \mathrm{M}$ phosphate-buffered saline (PBS). Then the Ficoll-Paque was layered on $30 \mathrm{ml}$ of the diluted blood. After centrifugation at $400 \times \mathrm{g}$ for $20 \mathrm{~min}$, the buffy coat layer containing PBMCs was extracted and resuspended in PBS. Human leukemia cell lines were obtained from The Japanese Cancer Research Resources Bank (Tokyo, Japan). They include lymphoid (T; Jurkat, CCRFCEM, B; BALL-1), myeloid (KG-1), erythroid (K562, HEL) and monocytic (J-111, U937) leukemia cell lines. Cells were kept in culture with RPMI1640 medium supplemented with $10 \%$ fetal calf serum, $100 \mathrm{IU}$ penicillin $\mathrm{G} / \mathrm{ml}$, and $100 \mu \mathrm{g}$ streptomycin/ $\mathrm{ml}$ in $5 \% \mathrm{CO}_{2} /$ air at $37^{\circ} \mathrm{C}$. On the day of the experiment, the cells were removed from the tissue culture flasks and washed three times with PBS.

\section{Northern blot hybridization}

Total RNA was isolated from the human PBMCs and the various cell lines by single-step acid guanidium thiocyanate-phenol-chloroform extraction [12]. Electrophoresis was performed with $10 \mu \mathrm{g}$ of the total RNA in a $0.4 \mathrm{M}$ formaldehyde$1 \%$ agarose gel. RNA was transferred to a nylon membrane (Schleicher and Schuell, Keene, $\mathrm{NH}$ ) and hybridized with a nick-translated ${ }^{32} \mathrm{P}$-labeled human POMC CDNA probe, which contained the entire exon 3 sequence, for $48 \mathrm{~h}$ at $62{ }^{\circ} \mathrm{C}$ as previously described [13]. The probe was synthesized by PCR, with cDNA reverse transcribed from human pituitary total RNA under standard conditions as previously described [14]. The PCR product of human POMC [corresponding to nucleotides (n) 226-718 of the published cDNA sequence] [15] was purified on an agarose gel, transferred to a DEAE-cellulose membrane (Shleicher \& Schnell), extracted, and desalted by
Centricon 30 (Amicon, Danvers, MA) centrifugation.

\section{RT-PCR-Southern analysis of POMC gene expression}

Total RNA was isolated from human normal PBMCs and hematological malignancy cell lines. The RNA $(2 \mu \mathrm{g})$ was reverse transcribed into cDNA with random primers (Takara Shuzo Co., Kyoto, Japan) and avian myeloblastosis virus reverse transcriptase (Life Sciences, Inc., Petersburg, FL) in a final volume of $20 \mu l$, as previously described [14]. The cDNA mixture was diluted to $\times 4$ with TE (10 mM Tris- $\mathrm{HCl}, 1 \mathrm{mM}$ EDTA) and stored at $-20^{\circ} \mathrm{C}$ until used. The cDNA was amplified by PCR, as previously described [14]. Briefly, one microliter of diluted single stranded cDNA (as a template) was combined with two primers ( $25 \mathrm{pmol}$ each) of different primer sets (primer set 1 or set 2), $1.5 \mathrm{mM}$ each deoxyribonucleoside triphosphate and 1.5 units of Taq polymerase (Perkin Elmer Cetus) in $1 \times$ PCR buffer [ $67 \mathrm{mM}$ tris- $\mathrm{HCl}, 6.7 \mathrm{mM}$ $\mathrm{MgCl}_{2}, 170 \mu \mathrm{g} / \mathrm{ml} \mathrm{BSA}, 16.6 \mathrm{mM}\left(\mathrm{NH}_{4}\right)_{2} \mathrm{SO}_{4}, 10 \%$ dimethylsulfoxide], in a total volume of $50 \mu$ l.

The $5^{\prime}$ primer of POMC primer set 1 was $5^{\prime}$ TCAGAGAGCAGCCTCCCGAG-3' corresponding to the $n$ 64-83 of the published exon 1 cDNA sequence [15]. The $3^{\prime}$ primer of POMC primer set 1 was $5^{\prime}$-CCTTCTTGTAGGCGTTCTTG-3' corresponding to the $n$ 699-718 of the published exon 3 cDNA sequence [15], and the expected size of the amplified fragment was $822 \mathrm{n}$. The $5^{\prime}$ primer of POMC primer set 2 was $5^{\prime}$-AGAAGCGCGAGG ACGTCTCA-3' corresponding to the $\mathrm{n}$ 226-245 of the published exon 3 cDNA sequence [15]. The $3^{\prime}$ primer of POMC primer set 2 was 5'-CCTTCTTGTA GGCGTTCTTG-3' corresponding to the $\mathrm{n}$ 699-718 of the published exon 3 cDNA sequence [15], and the expected size of the amplified fragment was $493 \mathrm{n}$. The cording region of ACTH is located in the $n$ 334-450 of the published exon 3 cDNA sequence [15], since this region should be amplified with primer sets 1 and 2 .

Thirty cycles of PCR for POMC (primer sets 1 and 2) were carried out with a thermal cycler (Sanko Junyaku, Tokyo, Japan) according to a step program of $80 \mathrm{sec}$ at $94{ }^{\circ} \mathrm{C}, 80 \mathrm{sec}$ at $49^{\circ} \mathrm{C}, 80 \mathrm{sec}$ at $72^{\circ} \mathrm{C}$, followed by a $15 \mathrm{~min}$ extension at $72{ }^{\circ} \mathrm{C}$. In this PCR condition, amplifications of POMC were performed within the linear amplification range. 
After amplification, eight microliters of the PCR mixture was electrophoretically separated on a $1.5 \%$ agarose gel. The gel was blotted onto nylon membrane (Biodyne A; Pall BioSupport, NY) by capillary transfer. Southern blot hybridization was performed according to the following procedure. PCR-generated POMC probes were labeled with digoxigenin (Dig; Boehringer Mannheim, Indianapolis, IN) by nick translation and was purified as previously described [16]. PCRamplified cDNA immobilized on the nylon membrane was hybridized with the Dig-labeled probe and a chemiluminescent detection with AMPPD (Tropix, Bedford, MA) was performed, as previously described [16]. Briefly, membranes were hybridized with $5 \times$ SSC ( $75 \mathrm{mM}$ sodium citrate, $750 \mathrm{mM}$ sodium chloride, $\mathrm{pH} 7.0$ ), $0.1 \% \mathrm{~N}$-lauroyl sarcosine, $0.02 \%$ sodium dodecyl sulfate, $50 \%$ formamide and $2 \%$ blocking agent (Boehringer Mannheim) for $20 \mathrm{~h}$ at $42{ }^{\circ} \mathrm{C}$. After posthybridization washes, the membranes were incubated with anti-Dig antibody (Boehringer Mannheim). The membranes were incubated with AMPPD, then exposed to X-ray film for 15-45 min.

Gene expression of $\beta$-actin was determined by the RT-PCR-Southern method in a previous report [17].

\section{Con- $A$ stimulation and ACTH RIA}

Jurkat and BALL-1 cells were seeded at $5 \times 10^{5} /$ $\mathrm{m} l$ and treated with or without Con-A $(1 \mu \mathrm{g} / \mathrm{ml})$. $72 \mathrm{~h}$ after cultivation, the culture medium was collected and evaporated. The samples were reconstituted in assay buffer, and the ACTH concentration was measured with an ACTH-IRMA kit (Mitsubishiyuka Co., Tokyo, Japan).

\section{Statistical analysis}

Statistical comparisons were made by one-way analysis of variance and Student's $t$-test, with $P<0.05$ considered significant.

\section{Results}

Northern blot analysis of POMC $m R N A$ in human $P B M C$ and leukemia cell lines

Although we attempted to examine POMC
mRNA in PBMC and various types of leukemia cell lines by Northern blot analysis, only Jurkat cells exhibited a faint hybridization signal for POMC mRNA (Fig. 1). The size of the full-length POMC mRNA was about $1200 \mathrm{n}$ long in the RNA from human anterior pituitary gland and human POMC-producing tumor (lane 1 and 2, Fig. 1), whereas the POMC mRNA found in the Jurkat cells appeared as a band of approximately $800 \mathrm{n}$ (lane 3, Fig. 1).

\section{RT-PCR analysis of POMC $m R N A$ in human $P B M C$ and Jurkat cell line}

Figure 2 shows the results of RT-PCR analysis for POMC mRNA in human PBMC and the Jurkat cell line. The use of POMC primer set 1 (corresponding to exon 1 to 3 ) failed to amplify POMC cDNA in either PBMC or Jurkat cells, although it was successful in amplifying POMC cDNA generated from human POMC-producing tumor. We obtained the same results when we used a POMC primer set corresponding to exon 2 to 3 (data not shown). By contrast, POMC cDNA was amplified by means of POMC primer set 2 (corresponding to exon 3 alone) in both PBMC and Jurkat cells.

\section{RT-PCR Southern analysis of POMC $m R N A$ expression in human leukemia cell lines}

To enhance the sensitivity of the detection of POMC mRNA, the RT-PCR Southern method was performed with total RNA from various types of

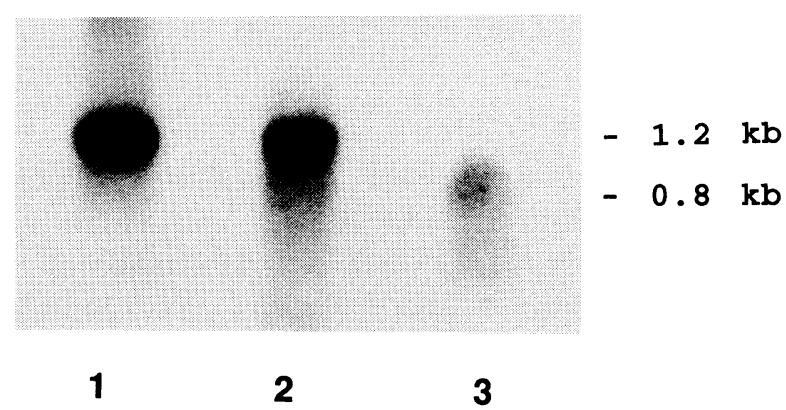

Fig. 1. Gene expression of POMC gene in the Jurkat cell line. Northern blot analysis of total RNA ( $1 \mu \mathrm{g}$ in lanes 1 and $2 ; 10 \mu \mathrm{g}$ in lane 3 ) isolated from various tissues was performed. 1. Ectopic ACTH producing tumor, 2. Normal human pituitary tissue, 3. Jurkat cell line. 


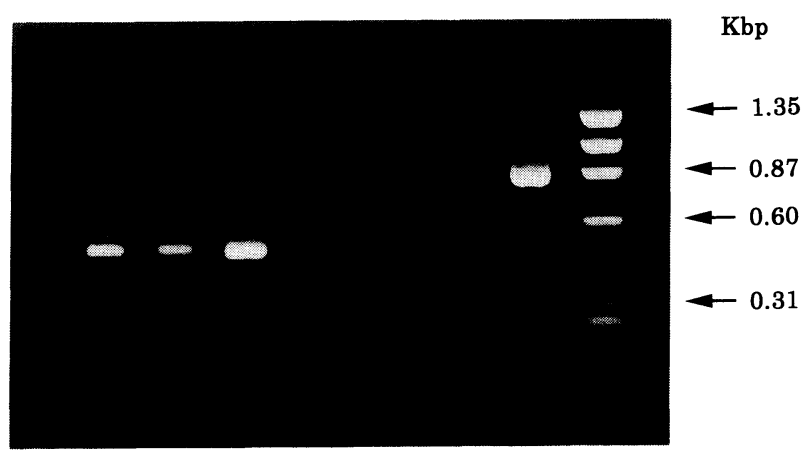

$\begin{array}{lllllll}7 & 6 & 5 & 4 & 3 & 2 & 1\end{array}$

Fig. 2. Detection of POMC transcripts in normal human lymphocytes and the Jurkat cell line by the RT-PCR method. Primer set 1 , which amplified exons 1 and 3 , was used in lanes 2-4. Primer set 2, which amplified only exon 3, was used in lanes 5-7. 1 . DNA size markers ( $ø$ X174/Hind III digestion) 2 and 5. Ectopic ACTH producing tumors, 3 and 6. Normal human lymphocyte 4 and 7 Jurkat cell lines.

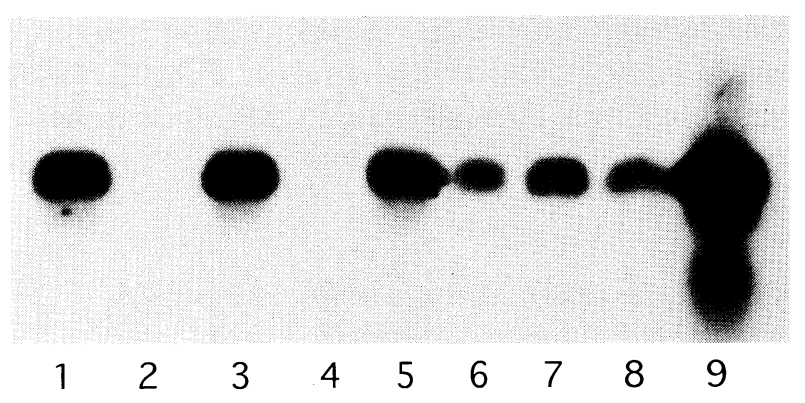

Fig. 3. Gene expression of POMC in various leukemia cell lines. RT-PCR-Southern blot analysis was performed with a Dig-labeled probe and by chemiluminesent reaction. 1. Jurkat, 2. J-111, 3. CCRF-CEM, 4. U937, 5. HEL, 6. KG-1, 7. BALL-1, 8. $\mathrm{K} 562$, 9. Ectopic ACTH producing tumor.

human leukemia cell lines. Control experiments in which reverse transcriptase was excluded showed no detectable POMC signal. Amplification of the internal control gene $\beta$-actin was constant in all samples (data not shown). A positive hybridization signal was detected in six cell lines, Jurkat, CCRF-CEM, BALL-1, HEL, K-562 and KG1 (Fig. 3). Two lines, J-111 and U937, did not show any hybridization signals for amplified POMC gene (Fig. 3). These results indicate that the truncated POMC gene is expressed not only in lymphoid cells
Table 1. Summary of truncated POMC mRNA expression in the various leukemia cell lines

\begin{tabular}{llc}
\hline Cell line & Origin of cell line & $\begin{array}{c}\text { truncated POMC } \\
\text { gene expression }\end{array}$ \\
\hline Jurkat & T lymphoid leukemia & ++ \\
CCRF-CEM & T lymphoid leukemia & ++ \\
BALL-1 & B lymphoid leukemia & + \\
KG-1 & Myeloid leukemia & + \\
K562 & Erythroid leukemia & + \\
HEL & Erythroid leukemia & ++ \\
J-111 & Monocytic leukemia & - \\
U937 & Monocytic leukemia & - \\
\hline
\end{tabular}

but also in erythroid and myeloid leukemia cells (Table 1).

\section{Effects of Con-A on POMC mRNA expression and} ACTH-like immunoreactivity in Jurkat and BALL-1 cell lines

The leukemia cell lines expressing POMC mRNA, Jurkat and BALL-1, were treated with Con-A (1 $\mu \mathrm{g} / \mathrm{ml}, 72 \mathrm{~h})$. The truncated POMC mRNA expression was stimulated (Fig. 4A) and ACTHlike immunoreactivity in the media was increased by the Con-A treatment (Fig. 4B).

\section{Discussion}

In the present study, we have shown that human PBMCs and leukemia cells express a POMC transcript lacking exons 1 and 2 (data not shown) which could be detected by the highly-sensitive RT-PCR method. Only one line, Jurkat, contained a significant amount of the truncated-POMC mRNA large enough to be detected by Northern blot analysis. These data are compatible with those in previous reports indicating that human PBMC contains a truncated-POMC mRNA including only exon 3 [11]. Lacaze-Masmonteil et al. have suggested that the truncated-transcript results from heterogenous start sites of transcription located between 41 and $162 \mathrm{n}$ downstream from the $5^{\prime}$ end of exon 3 [18]. Since previous studies have used normal PBMC which included mature T-, Blymphocytes and monocytes, the character of POMC-expressing cells has remained unclear. To clarify the nature of POMC-expressing cells, we 
A

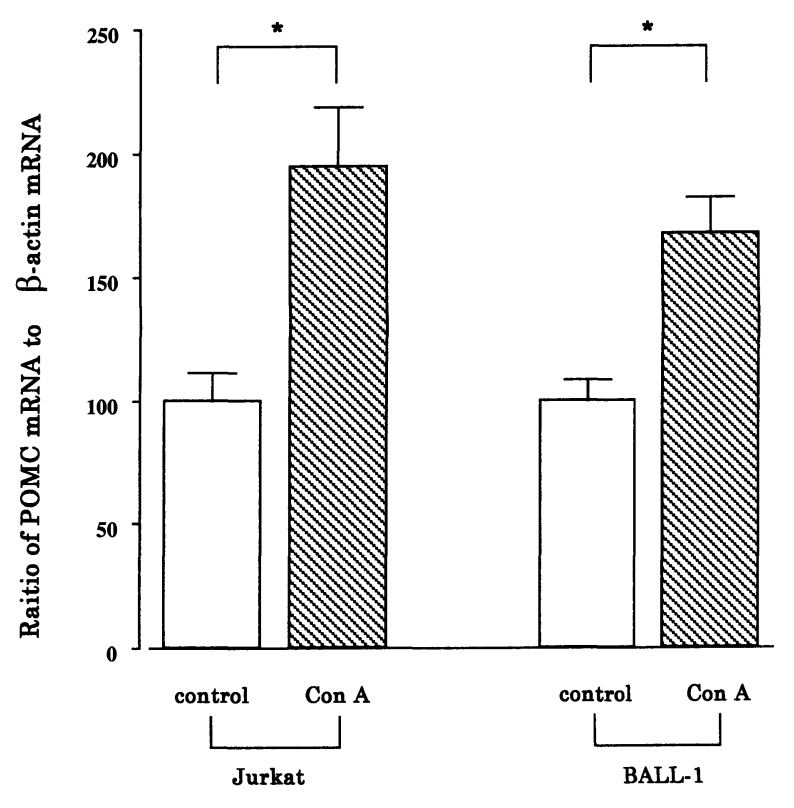

B

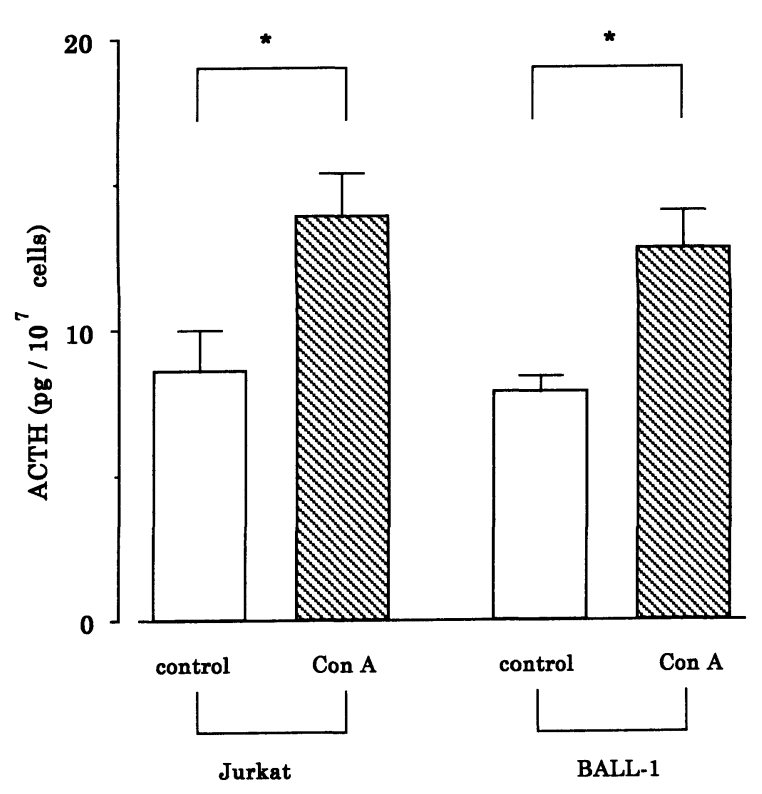

Fig. 4. Effects of Con A stimulation on POMC gene expression and ACTH secretion from leukemia cell lines. A: Leukemia cells were treated with vehicle or $1 \mu \mathrm{g} / \mathrm{ml}$ Con A for 3 days. POMC and $\beta$-actin gene expression was quantified by RT-PCR-Southern blot analysis in Jurkat and BALL-1 cell lines untreated or exposed to Con A. Data represent the average of three experiments. Vertical lines represent the SEM. The asterisk indicates a significant difference $(P<0.05)$. B: The ACTH concentration in the culture medium was measured with an ACTH-IRMA Kit in Jurkat and BALL-1 cells untreated or exposed to Con A. Data represent the average of three experiments. Vertical lines represent the SEM. The asterisk indicates a significant difference $(P<0.05)$.

used several leukemia cell lines derived from different cell lineages. Truncated POMC mRNA was detected by a highly-sensitive RT-PCR method in lymphoid, myeloid and erythroid leukemia cells as well as in PBMC. By contrast, neither monocytic leukemia line, J-111 or U937, expressed the truncated-POMC mRNA by our methods. Mechanick et al. [19] have reported that POMC mRNA may exist in a small subset of macrophages which originate in the peripheral blood monocytes. The peripheral blood monocyte, a precursor of the tissue macrophage, differs both functionally and phenotypically from the macrophage. In addition, it has been reported that different gene expression occurs in the macrophages depending on their location and state of activation as compared to the monocytes [20]. Although further studies are still required to decide whether or not human peripheral blood monocytes contain POMC mRNA, the selective suppression of POMC mRNA may occur in the immature monocytic leukemia cells.
Oates et al. [10] described the presence of a short POMC mRNA in Epstein-Barr virus-transformed human lymphocytes and Buzzetti et al. [11] also found the short POMC mRNA in mononuclear cells. Those RNA species are approximately 400-n shorter than that found in the pituitary and similar to that detected in extrapituitary tissues $[10,11]$. A previous study suggested that the 800-n mRNA, probably representing an RNA species lacking both exon 1 and 2 and part of the $5^{\prime}$ region of exon 3 , might not be translated into a truncated form of POMC which lacks a signal peptide necessary for membrane translocation and precursor processing [18]. Our study failed to detect the 1,200-n mRNA in PBMCs, and various types of leukemia cell lines do not exclude the possibility of the existence of this message which could be present in concentrations insufficient to be detected by our method. Although the major specie of POMC mRNA in human testis was 800-n, the presence of $1,200-n$ mRNA has been detected by a highly 
sensitive S1 nuclease mapping technique [18]. This raised the possibility that the POMC peptide present in extrapituitary tissues might derive from efficient translation of full-length POMC mRNA present in very low concentrations. To address whether the truncated form of POMC mRNA is translated to the POMC peptide or not deserves further investigation.

The expression of POMC mRNA in T and B leukemic cells was stimulated by a known PBMC activator, Con-A which had a mitogen activity on lymphocytes, in the present study. Although it should be noted that the RT-PCR method may not be suitable for quantitative analysis, the ACTHlike immunoreactivity was also increased in the culture media from the same cells by the Con-A treatment. We have performed a chromatographic characterization of ACTH-like immunoreactivity, while previous report showed that the Sephadex G-50 chromatographic profile of ACTH-like immunoreactivity identified the presence of 1-39
ACTH [11]. These data therefore suggest that POMC-derived peptides such as ACTH or endorphins might relate to cellular proliferation, at least in leukemia cells. Since it has been reported that ACTH and endorphins directly affect the growth of lymphocytes [21], the concept of autocrine/paracrine interactions mediated by POMC-derived peptides among the leukemic cells could be proposed. Although the physiological role of POMC-derived peptides in the hematopoietic cells is still largely unknown, the observation that Con-A stimulated POMC mRNA expression and ACTH-like immunoreactivity in leukemia cells might support the concept of autocrine/paracrine interactions in the cellular proliferation among cells mediated by POMCrelated peptides.

In conclusion, our results confirm the existence of a truncated-POMC mRNA in human PBMC and also in various hematological malignancy cells except monocytic leukemia cells.

\section{References}

1. Weigent DA, Blalock JE (1987) Interactions between the neuroendocrine and immune systems: Common hormones and receptors. Immunol Rev 100: 79-108.

2. Bost KL (1988) Hormone and neuropeptide receptors on mononuclear leukocytes. Progress in Allergy 43: 63.

3. Eipper BA, Mains RE (1980) Structure and biosynthesis of pro-adrenocorticotropin/endorphin and related peptides. Endocr Rev 1: 1-27.

4. Johnson HM, Torres BA, Smith EM, Dion LD, Blalock JE (1984) Regulation of lymphokine (gamma-interferon) production by corticotropin. J Immunol 132: 246-250.

5. Johnson HM, Smith EM, Torres BA, Blalock JE (1982) Regulation of the in vitro antibody response by neuroendocrine hormones. Proc Nalt Acad Sci USA 79: 4171-4174.

6. Alvarez-Mon M, Kehrl JH, Fauci AS (1985) A potential role for adrenocorticotropin in regulating human B lymphocyte functions. I Immunol 135: 3823-3826.

7. Johnson HM, Klimpel GR , Smith EM (1987) Adrenocorticotropin (ACTH) receptors on murine leukocytes: Expression and association with cellmediated cytotoxicity. Fed Proc 46: 1221.

8. Harbour-McMenamin D, Smith EM, Blalock JE (1985) Bacterial lipopolysaccharide induction of leukocyte-derived corticotropin and endorphins.
Infect Immun 48: 813-817.

9. Smith EM, Morrill AC, Meyer WJ, Blalock JE (1986) Corticotropin releasing factor induction of leukocyte-derived immunoreactive ACTH and endorphins. Nature 321: 881-882.

10. Oates EL, Allaway GP, Armstrong GR, Boyajian RA, Kehrl JH, Prabhakar BS (1988) Human lymphocytes produce pro-opiomelanocortin generelated transcripts. Effects of lymphotropic viruses. J Biol Chem 263: 10041-10044.

11. Buzzetti R, McLoughlin L, Lavender PM, Clark AJ, Rees LH (1989) Expression of pro-opiomelanocortin gene and quantification of adrenocorticotropic hormone-like immunoreactivity in human normal peripheral mononuclear cells and lymphoid and myeloid malignancies. J Clin Invest 83: 733-737.

12. Chomczynski P, Sacchi N (1987) Single-step method of RNA isolation by acid guanidinium thiocyanatephenol-chloroform extraction. Anal Biochem 162: 156-159.

13. Murao K, Sato M, Mizobuchi M, Niimi N, Ishida T, Takahara J (1994) Acute effects of hypoglycemia and hyperglycemia on hypothalamic growth hormone-releasind hormone and somatostatin gene expression in the rat. Endocrinology 134: 418-423.

14. Mizobuchi M, Murao K, Takeda R, Kakimoto $Y$ (1994) Tissue specific expression of isoaspartyl protein carboxyl methyltransferase gene in rat brain 
and testis. J Neurochem 62: 322-328.

15. Takahashi H, Teranishi $Y$, Nakanishi S, Numa S (1982) Isolation and structural organization of the human corticotropin-beta-lipotropin precursor gene. FEBS lett 135: 97-102.

16. Sato M, Murao K, Mizobuchi M, Takahara J (1993) Quantitative and sensitive Northern blot hybridization using PCR-generated DNA probes labeled with digoxigenin by nick translation BioTechniques 15: 880-882.

17. Fujita T, Yamaji $Y$, Sato M, Murao K, Takahara J (1994) Gene expression of somatostain receptor subtypes, SSTR1 and SSTR2, in human lung cancer cell lines. Life Sciences 55: 1797-1806.

18. Lacaze-Masmonteil T, de Keyzer Y, Luton JP, Kahn A, Bertagna $X$ (1987) Characterization of proopiomelanocortin transcripts in human nonpituitary tissues. Proc Natl Acad Sci USA 84: 7261-7265.

19. Mechanick JI, Levin N, Roberts JL, Autelitano DJ
(1992) Proopiomelanocortin gene expression in a distinct population of rat spleen and lung leukocytes. Endocrinology 131: 518-525.

20. Adams DO, Hamilton TA (1984) The cell biology of macrophage activation. Annu Rev Immunol 2: 283318.

21. Teschemacher $H$, Koch $G$, Scheffler H, Hildebrand A, Brantl V (1990) Opioid peptides. Immunological significance? Ann NY Acad Sci 594: 66-75.

22. Too CK, Cragoe EJ Jr, Friesen HG (1987) Amiloridesensitive $\mathrm{Na}+/ \mathrm{H}^{+}$exchange in rat $\mathrm{NB} 2$ node lymphoma cells. Stimulation by prolactin and other mitogens. Endocrinology 121: 1512-1520.

23. Mukherjee P, Mastro AM, Hymer WC (1990) Prolactin induction of interleukin-2 receptors on rat splenic lymphocytes. Endocrinology 126: 88-94.

24. McGillis JP, Park A, Rubin-Fletter P, Turck C, Dallman MF, Payan DG (1989) Stimulation of rat B-lymphocyte proliferation by corticotropinreleasing factor. J Neurosci Res 23: 346-352. 